УДК 94(470.51)"1941/1945":35(045)

\title{
Д.В. Репников
}

\section{К ВОПРОСУ ОБ ОСОБЕННОСТЯХ ДЕЯТЕЛЬНОСТИ УПОЛНОМОЧЕННЫХ ГОСУДАРСТВЕННОГО КОМИТЕТА ОБОРОНЫ В ГОДЫ ВЕЛИКОЙ ОТЕЧЕСТВЕННОЙ ВОЙНЫ (ПО ДОКУМЕНТАМ ФЕДЕРАЛЬНЫХ И РЕГИОНАЛЬНЫХ АРХИВОВ)}

Статья посвящена такому важному аспекту деятельности уполномоченных Государственного Комитета Обороны в годы Великой Отечественной войны, как конфликты полномочий. Противоречия между уполномоченными ГКО и руководителями партийных, государственных, хозяйственных органов разных уровней, а также между самими уполномоченными, находившие выражение в возникновении разного рода спорных ситуаций и нередко выливавшиеся в конфликты полномочий, стали обычным явлением в процессе функционирования системы органов государственной власти и управления СССР в военный период. На основе документов федеральных (ГА РФ, РГАСПИ, РГАЭ) и региональных (ЦГА УР, ЦДНИ УР) архивов автор рассматривает ситуацию конфликта полномочий, сложившуюся в годы Великой Отечественной войны в Удмуртской АССР, показывающую, что историческая действительность сложнее утвердившихся и распространённых по сей день упрощённых стереотипных представлений о ней.

Ключевые слова: Великая Отечественная война, Государственный Комитет Обороны, ГКО, уполномоченные ГКО, Удмуртская АССР, история Удмуртии.

DOI: $10.35634 / 2412-9534-2020-30-1-111-118$

Несмотря на наличие в современной отечественной историографии значительного количества публикаций, посвящённых функционированию высшего чрезвычайного органа государственной власти СССР периода Великой Отечественной войны - Государственного Комитета Обороны (ГКО), деятельность уполномоченных ГКО на сегодня изучена по-прежнему слабо. В статьях и монографических исследованиях общепринято положение о том, что для решения поставленных задач уполномоченные ГКО наделялись предельно широкими правами, закреплёнными в подписанных председателем ГКО И. В. Сталиным мандатах: всем гражданским (партийным, государственным, хозяйственным) и военным органам предписывалось оказывать им всяческое содействие в проводимых мероприятиях, любые их требования и распоряжения никем не могли быть взяты под сомнение и должны были выполняться неукоснительно*.

Соответственно этому, по сути, стереотипу среди исследователей утвердилось представление, что «об уполномоченных ГКО всё, в общем, уже известно и никаких принципиально новых открытий в этой области ожидать не следует». Однако полагаем, что подобный подход не вполне верен, ибо общее слагается из частностей, а именно они нам в основном неведомы. Частности позволяют реконструировать самый процесс деятельности уполномоченных ГКО, который, как свидетельствуют источники, имея свои особенности, носил, в итоге, более сложный характер и был далеко не столь гладким и однозначным, как это представляется на первый взгляд в контексте указанного стереотипа.

Данная статья как продолжение работы автора над изучением темы [5-10], преследует цель: введением в научный оборот новых документов о деятельности уполномоченных ГКО, выявленных в фондах федеральных (ГА РФ, РГАСПИ, РГАЭ) и региональных (ЦГА УР, ЦДНИ УР) архивов, расширить и детализировать представление о специфике функционирования этого чрезвычайного властного института периода Великой Отечественной войны.

\footnotetext{
* Следует, однако, иметь в виду, что, хотя мандаты формально и наделяли уполномоченных ГКО особым статусом с максимально широкими правами, последние всё-таки не следует абсолютизировать. На практике действие мандатов было ограничено пределами разумного и возможного. Так, В. С. Емельянов (уполномоченный ГКО по производству танков Т-60 и корпусов танков КВ на заводах наркомата танковой промышленности СССР в Челябинской области) описывает в мемуарах такую ситуацию. Когда ему срочно потребовалось полететь в Куйбышев, начальник аэропорта ничем не мог помочь, ибо в его распоряжении не было ни одного самолёта. В итоге, в нарушение установленного порядка, пришлось лететь грузовым бортом до Казани, а далее думать, как добираться до Куйбышева. «В аэропорту Казани не было никаких транспортных средств, и мой мандат не имел никакой силы. Единственное, что можно было сделать, - пройти к дороге и остановить какую-нибудь машину, идущую в город. Так я и поступил» [3, с. 68-69].
} 
Одной из особенностей деятельности уполномоченных ГКО было то, что по ходу выполнения возложенных на них обязанностей они периодически входили в противоречие с руководителями партийных, государственных, хозяйственных органов разных уровней, а также друг с другом. Возникавшие разного рода спорные ситуации, нередко выливались и в конфликты полномочий.

Подобная практика была, как правило, следствием обстановки, которая объективно складывалась под воздействием чрезвычайных условий военного времени. Суть её охарактеризована в документе, выявленном нами в материалах секретариата Л. П. Берия, собранных в фонде Совета министров СССР Государственного архива Российской Федерации. Это письмо «О положении директора предприятия и уполномоченного ГКО», направленное на имя Л. П. Берия уполномоченным ГКО по производству боеприпасов на заводах наркоматов боеприпасов и миномётного вооружения СССР в Челябинской области С. С. Дукельским 15 июля 1942 г. Хотя письмо описывает сложную административно-хозяйственную ситуацию, сложившуюся в конкретном регионе, полагаем, что его можно использовать и для характеристики особенностей деятельности уполномоченных ГКО в целом.

Автор письма констатирует: «Положение директора - архитрудное: множество наблюдающих, контролирующих и помогающих - три секретаря обкома по военной промышленности, три отдела плюс штат инструкторов, горкомы плюс штат инструкторов, райкомы. Кроме местных работников уполномоченные ГОКО по разным отраслям, уполномоченные ЦК, КПК, госконтроля, представители наркоматов. Все связываются с директором, требуют, начиная от сведений за истекшие сутки и кончая объяснениями директора, в зависимости от выполнения графика, часто с личным вызовом. Директор теряет много времени, лавирует, старается угодить всем и нередко примирить противоречивые требования... Уполномоченных много и к ним привыкли, мало считаются. В условиях, когда обком, с широко разветвлённым аппаратом, тесно связан с предприятиями, создаётся двойственность. Пример из моей практики: Мехаев - секретарь по боеприпасам всегда появляется за мной на заводах и в Челябинске, и в Копейске, и в Кургане (заводы №№ 62, 549, 114, 258, 603 и 707), где оба мы сталкивались чуть ли ни в дверях. Ограничить нельзя и нецелесообразно: функция Мехаева - боеприпасы, он имеет разветвлённый аппарат, имеет возможность партийного воздействия. Но положение уполномоченного - ложное и перед директором, и перед обкомом (горкомом). По заводу им. Колющенко даже два уполномоченных: один ведает боеприпасами в целом (Дукельский), а другой только M-13 (Соколов). Взаимодискредитация неизбежна. К тому же ведёт несовместимое совместительство второго секретаря обкома ВКП(б) т. Баранова: он - секретарь обкома по оборонной промышленности является одновременно уполномоченным ГОКО по заводу № 78. Пример: майская история с явно незаконной передачей заводом им. Колющенко 10 тыс. деталей для сборки М-13 заводу № 78, который, наоборот, по решению ГОКО обязан был и имел возможность поставить заводу им. Колющенко детали для сборки М-13. Тов. Баранов вызывал в обком сопротивлявшегося директора завода им. Колющенко - Полянцева, грозил ему разными карами и в конце концов решением обкома ВКП(б) понудил незаконно передать эти детали» [2, ф. р-5446, оп. 113, д. 11, л. 303-304].

Из приведённого текста очевидно, что стратегическое значение оборонной промышленности Южного Урала требовало максимального ускорения её работы по выпуску необходимой для фронта военной продукции. Отсюда и такое количество уполномоченных ГКО и иных проверяющих и контролирующих лиц, выполнявших функции «толкачей». Это неизбежно привело не только к пересечению и дублированию их функций, но и к банальной путанице, а в конечном итоге, к возникновению спорных ситуаций и конфликтов полномочий, совершенно не способствовавших решению задач эффективной организации военного производства. Поэтому с целью скорейшей нейтрализации отрицательного влияния сложившейся обстановки на работу оборонной промышленности Челябинской области С. С. Дукельский предложил рассмотреть вопрос об оптимизации корпуса «толкачей»: «1. Резко сократить количество инстанций и количество лиц, которым подотчётен директор... 2. Ограничиться одним уполномоченным ГОКО по боеприпасам... 3. Освободить секретаря обкома ВКП(б) по оборонной промышленности от несовместимых обязанностей уполномоченного ГОКО. 4. Отозвать второго уполномоченного ГОКО по заводу им. Колющенко» [2, ф. p-5446, оп. 113, д. 11, л. 304-305].

Л. П. Берия ознакомился с письмом С. С. Дукельского, о чём свидетельствует соответствующая пометка сотрудника его секретариата. Однако какие решения впоследствии были приняты, выяснить не удалось. Можно предположить, что, как и в иных известных нам похожих случаях, описанная ситуация также была разрешена в интересах налаживания нормальной работы оборонных предприятий Челябинской области. 
Спорные ситуации и конфликты полномочий в каждом конкретном случае имели, безусловно, свою специфику. Тем не менее, на основании выявленных нами на сегодняшний день архивных документов и сведений мемуарных источников условно можно разделить их на две группы.

Первую группу составляют конфликты полномочий, обусловленные распространённой в годы войны практикой принятия уполномоченными ГКО решений «под свою ответственность» [13, с. 319] без согласования с центральными органами государственного управления и/или их учреждениями на местах. Они принимались уполномоченными ГКО в силу острой необходимости, требовавшей скорейшего принятия практических мер по решению конкретных задач обороны страны и не оставлявшей времени на проволочки, которые могли возникнуть при соблюдении формальностей, согласованиях и др. Примером такого рода приведём, во-первых, конфликт между уполномоченным ГКО по производству танков Т-60 и корпусов танков КВ на заводах наркомата танковой промышленности СССР в Челябинской области В. С. Емельяновым и наркомом танковой промышленности, зампредседателя СНК СССР В. А. Малышевым [3, с. 69-73; 9, с. 68-69]. Во-вторых - конфликты, возникавшие в 1941-1942 гг. между уполномоченным ГКО по Удмуртской АССР А. П. Чекиновым и руководством уральских региональных хозяйственных органов (Уральского территориального управления государственных материальных резервов и Свердловской конторы Главметаллосбыта) [14, ф. 300, оп. 1 , д. 4 , л. 53 ; д. 11 , л. 352; 7, с. 658-659]. В обоих случаях принятые уполномоченными ГКО «под свою ответственность» решения способствовали скорейшему проведению в жизнь постановлений ГКО и, в конечном итоге, отвечали интересам организации обороны страны, вследствие чего конфликтные ситуации были разрешены в пользу уполномоченных ГКО.

Вторую групnу составляют конфликты полномочий, возникавшие по причине некомпетентности или неадекватного применения отдельными уполномоченными ГКО предоставленных им прав, проявлявшихся в принятии ими волюнтаристских решений, нередко оборачивавшихся значительными издержками и потерями. В этом случае примером могут послужить, во-первых, конфликт между замнаркома авиационной промышленности СССР, авиаконструктором А. С. Яковлевым, направленным в октябре 1941 г. в Новосибирск на завод № 153 им. В. П. Чкалова НКАП СССР с заданием в кратчайший срок организовать производство истребителей, и уполномоченным ГКО, который в тот момент уже находился на заводе [16, с. 300-302; 9, с. 69]. Во-вторых - конфликт между замнаркома лесной промышленности СССР Т. Ф. Трудовым, в 1944 г. - уполномоченным ГКО по лесозаготовкам по Архангельской области, и руководством обкома ВКП(б) в лице первого секретаря Г. П. Огородникова $[11$, ф. 17, оп. 122 , д. 75 , л. $1-9,18 ; 6$, с. 58-59]. Подобного рода конфликтные ситуации разрешались освобождением уполномоченных ГКО от занимаемых должностей.

Именно такой конфликт полномочий развился в 1942 г. в Удмуртской АССР в связи с активной деятельностью уполномоченного ГКО Г. М. Тараскевича, дважды назначавшегося таковым в республику. 21 февраля 1942 г. постановлением ГКО № 1319с «О поставке дров для железных дорог» Г. М. Тараскевич был назначен уполномоченным ГКО по дровозаготовкам по Удмуртской АССР. Но ещё до истечения срока своих полномочий (1 июня 1942 г.) 26 апреля 1942 г. постановлением ГКО № 1656с «Об обеспечении дровами завода № 71 Наркомвооружения» он назначается уполномоченным ГКО вторично: по поставке дров заводу № 71 [11, ф. 644, оп. 1, д. 21, л. 139-151; д. 32, л. 9-10].

Активная деятельность Г. М. Тараскевича в Удмуртской АССР отмечена серией изданных им приказов, сохранившихся в архивах республики $[14$, ф. 16, оп. 1, д. 3495 , л. 47a-47a об, 93-94; д. 3496, л. 113-114]. Так он реализовывал предоставленные ему ГКО права: «издавать приказы, обязательные для всех частных и должностных лиц»; «отстранять виновных от занимаемых должностей»; «за особо тяжкие проступки и преступления предавать суду для привлечения к ответственности по законам военного времени» [11, ф. 644, оп. 1, д. 21, л. 143; д. 64, л. 9].

Заметим, однако, что, кроме Г. М. Тараскевича, никто из действовавших в военный период в Удмуртской АССР временных уполномоченных ГКО (А. Г. Краснов, П. И. Ковалёв, И. И. Антощенко, М. П. Антонов, А. В. Тронин), не издавал подобных приказов (во всяком случае, среди архивных документов таковых нами пока не найдено). Они работали по-другому. Например, уполномоченный ГКО по дровоснабжению транспорта по Удмуртской АССР П. И. Ковалёв регулярно проводил производственные совещания руководителей лесной отрасли республики, протоколы которых также сохранились в региональных архивах [15, ф. р-784, оп. 1, д. 63, л. 54].

Казалось бы, в этом нет ничего необычного, и Г. М. Тараскевич просто-напросто значительно активнее работал, был именно «толкачом». Между тем, архивные документы указывают на другое. 
Во-первых, они позволяют сделать вывод, что уполномоченный ГКО занимался не только «толкачеством», но зачастую и «рвачеством». В частности, обвинял иных руководителей местных партийных и советских органов, лесозаготовительных организаций в том, что работали «исключительно плохо», «позорно», сознательно «стали на путь явного срыва постановления ГКО и извращения его на практике», и использовал по отношению к ним понятия «преступник», «оппортунист», «дезорганизатор», «гнилой либерал». Повинным в невыполнении его распоряжений и в срыве заданий ГКО в лучшем случае объявлял «строгий выговор с предупреждением», что «будут привлечены к строгой ответственности», в худшем - приказывал «снять с работы» и/или «предать суду по законам военного времени» [14, ф. 16, оп. 1, д. 3495, л. 47a-47a/oб, 93-94; д. 3496, л. 113-114; ф. 228, оп. 1, д. 2, л. 36-36об].

Кроме того, Г. М. Тараскевич, по-видимому, страдал повышенным честолюбием: по свидетельству уполномоченного КПК при ЦК ВКП(б) по Удмуртской АССР В. Н. Миронова, «во всех случаях разговор т. Тараскевича сводился к тому, что заготовка дров проходит удовлетворительно только благодаря его напористости, а обком ВКП(б), в лице секретаря т. Чекинова, и СНК Удмуртской АCСР, в лице председателя т. Тронина, никакой решительности в этих вопросах не проявляют» [14, ф. 228 , оп. 1 , д. 84 , л. 56].

Подобные действия и приказы Г. М. Тараскевича часто вызывали несогласие и протест местных партийных, советских и хозяйственных руководителей, которые считали его обвинения необоснованными, а действия незаконными, и писали жалобы в региональные и центральные инстанции.

Во-вторых, архивные документы свидетельствуют, что жалобы на «незаконные действия» уполномоченного ГКО поступали и по другой причине: Г. М. Тараскевич злоупотреблял своим служебным положением, периодически занимаясь «самоснабжением» продовольственными и хозяйственными товарами. Так, управляющий трестом «Удмуртлеспродторг» А. А. Карандашов в жалобах, направленных 28 апреля и 5 мая 1942 г. соответственно замнаркома лесной промышленности СССР Меньшикову (копия - управляющему «Союзлеспродторга» Виноградову) и наркому М. И. Салтыкову (копия - первому секретарю Удмуртского обкома ВКП(б) А. П. Чекинову) сообщал, что без его ведома и распоряжения (и письменного, и устного) Г. М. Тараскевич в порядке «самоснабжения» вытребовал в различных хозяйственных службах треста: 2 кг мёда на пасеке треста на ст. Чур, две пары валенок на складе Ижевской конторы треста в феврале и значительный объём продукции на базе треста в апреле (4 кг сливочного масла, 11 кг сахара, 15 кг кетовой икры, 1,250 кг чая, 4,8 кг рыбы, 4 кг хозяйственного мыла). «В бытность его в командировке в г. Сарапуле и на ст. Ува, где находится наша леспродконтора, ...он захватил также много продуктов, не брезгуя крупой, мукой и т. п.». «Кроме этого он заявил, <..> чтобы ему я приготовил “посылку” с продуктами в килограммах: мяса — 25 , муки пшеничной - 20, сливочного масла - 5, сахара - 10, икры, колбасы, махорки и для сопровождения этой посылки направить с ним нашего представителя, что он только тогда сумеет направить вагон спичек, которые мы не получаем в течении последних 6-ти месяцев. Что мной было не выполнено». «На мои протесты Тараскевич заявил: “Я питался и буду питаться, а торговая сеть меня не удовлетворяет”. Считаю действия Тараскевича неправильными и прошу дать надлежащие указания» [14, ф. 16, оп. 1, д. 3495, л. 107-108об].

М. И. Салтыков командировал для разбирательства представителя наркомата - инспектора Фельманна [14, ф. 228, оп. 1, д. 2, л. 34], однако о результатах его командировки ничего неизвестно. Судя по всему, на поведение Г. М. Тараскевича это никак не повлияло. Напротив, в ответ на жалобы, приказом уполномоченного ГКО от 20 мая 1942 г. А. А. Карандашов был снят с должности управляющего трестом «Удмуртлеспродторг» «за развал работы общественного питания и децзаготовок, неукомплектование торговой сети честными работниками и сгноение 60 тонн картофеля» [14, ф. 16, оп. 1, д. 3496, л. 113-114].

В свою очередь, А. А. Карандашов в объяснительной записке первому секретарю Удмуртского обкома ВКП(б) А. П. Чекинову от 22 мая 1942 г. указал на необоснованность обвинений Г. М. Тараскевича, поскольку истинными «причинами снятия меня с работы послужили не мотивы, указанные в приказе (это формальная придирка), а невыполнение мною его личных требований по самоснабжению и мои жалобы на использование уполномоченным ГКО Тараскевичем своего служебного положения в целях самоснабжения и растаскивания продуктов. <..> Обращаясь к Вам, считаю, что Вы соответствующе оцените поведение и поступок Тараскевича, как антипартийный, т. к. из-за личных интересов он шельмует меня как члена партии и работника» [14, ф. 16, оп. 1, д. 3496, л. 115-115oб]. 
4 июня 1942 г. А. П. Чекинов направил секретарю ЦК ВКП(б) А. А. Андрееву записку следующего содержания: «Считая, что уполномоченный ГОКО по тресту “Ижлес" тов. Тараскевич присваивает в своей работе несвойственные ему функции и непрерывным дёрганием людей только мешает делу, прошу Вас дать указание об отзыве тов. Тараскевича с работы в Удмуртской АССР. Должен сообщить, что мои просьбы к тов. Тараскевичу бросить “приказоманию”, перестать дёргать людей и работать в контакте с обкомом ВКП(б) - результата не дали» [14, ф. 16, оп. 1, д. 3484, л. 110].

КПК при ЦК ВКП(б) провела проверку через свои местные органы: в августе 1942 г. уполномоченный Комиссии по Удмуртской АССР В. Н. Миронов опросом руководителей лесозаготовительных организаций на местах, тоже писавших жалобы на Г. М. Тараскевича, подтвердил факты самоснабжения уполномоченного ГКО и «присваивания им несвойственных его работе функций» $[14$, ф. 228 , оп. 1 , д. 2, л. 34-36об; д. 43, л. 2; д. 84, л. 56].

В итоге, в октябре 1942 г. Г. М. Тараскевич был отозван в Москву и освобождён от обязанностей уполномоченного ГКО [14, ф. 228, оп. 1, д. 43, л. 30; д. 84, л. 56].

По исчерпании этой конфликтной ситуации руководство наркомата лесной промышленности СССР было вынуждено на примере Г. М. Тараскевича разъяснять вновь назначаемым уполномоченным ГКО по дровозаготовкам как им не надо работать. Об этом свидетельствует выявленная нами в фонде наркомата лесной промышленности СССР Российского государственного архива экономики стенограмма совещания у наркома М. И. Салтыкова от 4 ноября 1942 г. В частности, он (не называя фамилии) указал, что уполномоченный ГКО «задание обеспечил, но наделал там много глупостей, $<\ldots>$ поставил себя в такое положение, что пришлось его дело разбирать в Комиссии партийного контроля при ЦК. Я рекомендую избегать таких явлений» [12, ф. 7637, оп. 1, д. 261, л. 59-59об].

В 1943 г. Г. М. Тараскевич вновь назначается уполномоченным ГКО: по лесозаготовкам по Новосибирской области [11, ф. 644, оп. 1, д. 85, л. 79].

Вышеизложенное позволяет сделать следующие обобщающие выводы.

Первое. Применительно к деятельности уполномоченных ГКО в годы Великой Отечественной войны можно говорить о существовании двух вариантов рабочих стилей, осуществление которых на практике зависело от личностного фактора: конструктивного и волюнтаристского.

Конструктивный стиль выражался в способности и стремлении уполномоченных ГКО устанавливать на местах плодотворные рабочие взаимоотношения с региональными и местными организациями и решать актуальные задачи обороны страны посредством принятия коллективных согласованных решений. Для иллюстрации этого стиля можно привести примеры из мемуарных источников. Так, И. Д. Папанин - уполномоченный ГКО по перевозкам на Севере и организации погрузкивыгрузки в Архангельском морском порту, прибыв осенью 1941 г. в Архангельск, «тут же позвонил секретарю обкома партии Огородникову и попросил его созвать наутро руководящих работников области и города. Я хотел, чтобы руководители области знали: я не собираюсь выполнять свои обязанности автономно, а намерен действовать в тесном контакте с областной партийной организацией и органами Советской власти, с военным командованием и руководителями ведомств, что надеюсь на их поддержку и помощь. Без этого моя миссия заранее была бы обречена на провал» [4, с. 244].

Аналогичным образом действовал А. А. Ветров - уполномоченный ГКО по Сталинградскому тракторному заводу им. Ф. Э. Дзержинского наркомата тяжёлого машиностроения СССР. По прибытии в Сталинград в июле 1941 г., он первым делом направился в обком ВКП(б): «Ведь прежде чем приступить к исполнению своих новых обязанностей, мне нужно было представиться местному партийному руководству, узнать его мнение о положении дел на заводе, заручиться поддержкой на будущее» [1, с. 45].

Примером волюнтаристского рабочего стиля стала деятельность Т. Ф. Трудова в Архангельской области, который, «используя права, предоставленные ему как уполномоченному ГКО... стал на путь подмены партийных и советских органов области», «полного игнорирования указаний и решений обкома ВКП(б) и облисполкома» $[11$, ф. 17, оп. 122, д. 75, л. 2-4, 9]; и Г. М. Тараскевича в Удмуртской АССР, который увлёкся «приказоманией» и «присваиванием несвойственных своей работе функций», и, в итоге, так и не сумел наладить контакт с руководством республики.

Bторое. Утвердившееся в историографии представление о чрезвычайных органах государственной власти СССР периода Великой Отечественной войны как об изначально безупречно работавшей системе - не вполне соответствующий историческим реалиям стереотип, упрощённая и идеализированная схема. Система не была совершенной. Конкретные и самые разнообразные жизненные обстоятельства перманентно корректировали процесс её функционирования, а стремление макси- 
мально быстро и оперативно решать задачи организации обороны страны, так или иначе, порождало накладки и сбои в виде дублирования функций, пересечения интересов, возникновения спорных ситуаций и конфликтов полномочий, отягощавшихся действием пресловутого «человеческого фактора». Таким образом, итоговая эффективность системы не была заложена в ней априори, но формировалась тяжёлой повседневной практикой, методом проб и ошибок.

\section{СПИСОК ИСТОЧНИКОВ И ЛИТЕРАТУРЫ}

1. Ветров А. А. Так и было. М.: Воениздат, 1982.159 с.

2. Государственный архив Российской Федерации (ГА РФ).

3. Емельянов В. С. С чего начиналось. М.: Советская Россия, 1979. 321 с.

4. Папанин И. Д. Лёд и пламень. М.: Политиздат, 1977. 416 с.

5. Репников Д. В. Деятельность уполномоченного ГКО по Удмуртской АССР в годы Великой Отечественной войны (по документам ЦДНИ УР) // История Удмуртии XX века в документах ЦДНИ УР: тез. докл. и выступ. участников науч.-метод. семинара, 26 окт. 2004 г. Ижевск, 2005. С. 51-55.

6. Репников Д. В. Институт уполномоченных ГКО: функции и положение в системе органов государственной власти и управления СССР периода Великой Отечественной войны // Вестн. Помор. ун-та. Сер. Гуманит. и соц. науки. 2008. № 11. С. 56-59.

7. Репников Д. В. Институт уполномоченного ГКО в Удмуртской АССР в годы Великой Отечественной войны: функции и положение в системе органов государственной власти и управления // Россия и Удмуртия: история и современность: материалы Междунар. науч.-практ. конф., посвящ. 450-летию добровольного вхождения Удмуртии в состав Российского гос-ва, Ижевск, 20-22 мая 2008 г. Ижевск: Удмурт. ун-т, 2008. С. 654-662.

8. Репников Д. В. «Постоянные» и «временные» уполномоченные ГКО в Удмуртской АССР в годы Великой Отечественной войны (к постановке проблемы) // Вестн. Удм. ун-та. Сер. История и филология. 2009. Вып. 2. C. $148-155$.

9. Репников Д. В. Уполномоченные Государственного Комитета Обороны в мемуарной литературе о Великой Отечественной войне: механизм назначения и функционирования // Вестн. Удм. ун-та. Сер. История и филология. 2012. Вып. 3. С. 63-72.

10. Репников Д. В. Чрезвычайные органы власти в Удмуртской АССР в годы Великой Отечественной войны // Патриотизм - духовный потенциал Великой Победы: материалы Респ. науч.-практ. конф., посвящ. 70-й годовщине Победы в Великой Отечественной войне 1941-1945 гг. (Ижевск, 29-30 апр. 2015 г.) Ижевск: УИИЯЛ УрО РАН, 2015. С. 28-33.

11. Российский государственный архив социально-политической истории (РГАСПИ).

12. Российский государственный архив экономики (РГАЭ).

13.Хмелевский К. М. На пороховом заводе // Кузница Победы: подвиг тыла в годы Великой Отечественной войны. Очерки и воспоминания. М.: Политиздат, 1980. 423 с.

14. Центр документации новейшей истории Удмуртской Республики (ЦДНИ УР).

15. Центральный государственный архив Удмуртской Республики (ЦГА УР).

16. Яковлев А. С. Цель жизни. М.: Политиздат, 1973. 608 с.

Поступила в редакцию 20.09.2019

Репников Дмитрий Викторович, кандидат исторических наук, доцент кафедры философии и гуманитарных дисциплин ФГБОУ ВО «Удмуртский государственный университет» 426034, Россия, г. Ижевск, ул. Университетская, 1 (корп. 6)

E-mail: repnikov@udm.ru

\section{D.V. Repnikov}

ON THE SPECIFICS OF THE ACTIVITIES OF THE PLENIPOTENTIARIES OF THE STATE DEFENSIVE COMMITTEE DURING THE GREAT PATRIOTIC WAR (ACCORDING TO DOCUMENTS OF FEDERAL AND REGIONAL ARCHIVES)

DOI: $10.35634 / 2412-9534-2020-30-1-111-118$

The article is devoted to such an important aspect of the activities of the plenipotentiaries of the State Defensive Committee during the Great Patriotic War, as conflicts of authority. Contradictions between the plenipotentiaries of the State Defensive Committee and the leaders of party, state, economic bodies at various levels, as well as between the plenipo- 
tentiaries themselves, that were expressed in the emergence of various disputes and often resulted in conflicts of authority, became commonplace in the functioning of the state power system of the USSR in the war period. Based on documents from federal (State Archive of the Russian Federation, Russian State Archive of Socio-Political History, Russian State Archive of Economics) and regional (Central State Archive of the Udmurt Republic, Center for Documentation of the Recent History of the Udmurt Republic) archives, the author considers a conflict of authority situation that developed during the Great Patriotic War in the Udmurt Autonomous Soviet Socialist Republic, which shows that historical reality is more complicated than the stereotypical manifestations of it.

Keywords: Great Patriotic War, State Defensive Committee, plenipotentiaries of the State Defensive Committee, Udmurt Autonomous Soviet Socialist Republic, history of Udmurtia.

\section{REFERENCES}

1. Vetrov A. A. Tak i bylo. [So it was]. Moscow, "Voenizdat" Publ., 1982, 159 p. (In Russian).

2. Gosudarstvennyj arhiv Rossijskoj Federatsii (GA RF) [The State Archive of the Russian Federation]. (in Russian, unpublished).

3. Emel'yanov V. S. S chego nachinalos' [How it began]. Moscow, "Sovetskaya Rossiya” Publ., 1979, 321 p. (In Russian).

4. Papanin I. D. Lyod i plamen' [Ice and flame]. Moscow, "Politizdat" Publ., 1977, 416 p. (In Russian).

5. Repnikov D. V. Deyatel'nost' upolnomochennogo GKO po Udmurtskoy ASSR v gody Velikoy Otechestvennoy voyny (po dokumentam TSDNI UR) [The activities of the plenipotentiaries of the State Defensive Committee of the Udmurt Autonomous Soviet Socialist Republic during the Great Patriotic War (according to the documents of the Center for Documentation of Recent History of the Udmurt Republic)]. Istoriya Udmurtii XX veka v dokumentakh Tsentra dokumentatsii noveyshey istorii Udmurtskoy Resrubliki: tezisy dokladov i vystupleniy uchastnikov nauchno-metodicheskogo seminara, 26 oktyabrya 2004 goda [The History of Udmurtia of the 20th Century in the Documents of the Center for Documentation of the Recent History of the Udmurt Republic: Theses of reports and speeches of participants in the scientific and methodical seminar, October 26, 2004]. Izhevsk, 2005, pp. 51-55. (In Russian).

6. Repnikov D. V. Institut upolnomochennyh GKO: funktsii i polozhenie v sisteme organov gosudarstvennoj vlasti i upravleniya SSSR perioda Velikoj Otechestvennoj vojny [Institute of the plenipotentiaries of the State Defensive Committee: functions and position in the state power system of the USSR during the Great Patriotic War]. Vestnik Pomorskogo universiteta. Seriya Gumanitarnyye i sotsial'nyye nauki [Bulletin of the Pomeranian University. Series Humanities and Social Sciences], 2008, no. 11, pp. 56-59. (In Russian).

7. Repnikov D. V. Institut upolnomochennogo GKO v Udmurtskoj ASSR v gody Velikoj Otechestvennoj vojny: funkcii i polozhenie v sisteme organov gosudarstvennoj vlasti i upravleniya [Institute of the plenipotentiary of the State Defensive Committee in the Udmurt Autonomous Soviet Socialist Republic during the Great Patriotic War: functions and position in the state power system]. Rossiya i Udmurtiya: istoriya i sovremennost': materialy mezhdunarodnoy nauchno-prakticheskoy konferentsii, posvyashchonnoy 450-letiyu dobrovol'nogo vkhozhdeniya Udmurtii v sostav Rossiyskogo gosudarstvava, Izhevsk, 20-22 maya 2008 goda [Russia and Udmurtia: history and modernity: materials of the International scientific and practical conference dedicated to the 450th anniversary voluntary entry of Udmurtia into the Russian state, Izhevsk, May 20-22, 2008]. Izhevsk, Udmurt University Press, 2008, pp. 654-662. (In Russian).

8. Repnikov D. V. "Postoyannye" i "vremennye" upolnomochennye GKO v Udmurtskoj ASSR v gody Velikoj Otechestvennoj vojny (k postanovke problemy) ["Permanent" and "temporary" plenipotentiaries of the State Defensive Committee in the Udmurt Autonomous Soviet Socialist Republic during the Great Patriotic War (to pose the problem)]. Vestnik Udmurtskogo universiteta. Seriya Istoriya i filologiya [Bulletin of the Udmurt University. Series History and Philology], 2009, issue 2, pp. 148-155. (In Russian).

9. Repnikov D. V. Upolnomochennye Gosudarstvennogo Komiteta Oborony v memuarnoj literature o Velikoj Otechestvennoj vojne: mekhanizm naznacheniya i funkcionirovaniya [Plenipotentiaries of the State Defensive Committee in the memoirs on the Great Patriotic War: the mechanism of appointment and functioning]. Vestnik Udmurtskogo universiteta. Seriya Istoriya i filologiya [Bulletin of the Udmurt University. Series History and Philology], 2012, issue 3, pp. 63-72. (In Russian).

10. Repnikov D. V. Chrezvychajnye organy vlasti v Udmurtskoj ASSR v gody Velikoj Otechestvennoj vojny [Extraordinary authorities in the Udmurt Autonomous Soviet Socialist Republic during the Great Patriotic War]. Patriotizm - dukhovnyy potentsial Velikoy Pobedy: materialy Respublikanskoy nauchno-prakticheskoy konferentsii, posvyashchonnoy 70-y godovshchine Pobedy v Velikoy Otechestvennoy voyne 1941-1945 godov (Izhevsk, 29-30 aprelya 2015 goda) [Patriotism - the inner potential of the Great Victory: materials of the Republican scientificpractical conference dedicated to the 70th anniversary of the Victory in the Great Patriotic War of 1941-1945. (Izhevsk, April 29-30, 2015)]. Izhevsk, Ed. of the Udmurt Institute of History, Language and Literature of Ural Branch of the RAS, 2015, pp. 28-33. (In Russian). 
11. Rossijskij gosudarstvennyj arhiv social'no-politicheskoj istorii (RGASPI) [Russian State Archive of Socio-Political History]. (in Russian, unpublished).

12. Rossijskij gosudarstvennyj arhiv ekonomiki (RGAE) [Russian State Archive of Economics]. (in Russian, unpublished).

13. Hmelevskij K. M. Na porohovom zavode [At the powder factory]. Kuznica Pobedy: podvig tyla v gody Velikoj Otechestvennoj vojny. Ocherki i vospominaniya [Forge of Victory: the feat of the rear during the Great Patriotic War. Essays and memories]. Moscow, "Politizdat" Publ., 1980, 423 p. (In Russian).

14. Tsentr dokumentacii novejshej istorii Udmurtskoj Respubliki (TSDNI UR) [Center for Documentation of Recent History of the Udmurt Republic]. (in Russian, unpublished).

15. Tsentral'nyj gosudarstvennyj arhiv Udmurtskoj Respubliki (TSGA UR) [Central State Archive of the Udmurt Republic]. (in Russian, unpublished).

16. Yakovlev A. S. Tsel' zhizni [The purpose of life]. Moscow, "Politizdat” Publ., 1973, 608 p. (In Russian).

Received 20.09.2019

Repnikov D. V., Candidate of History, Associate Professor of the Department of Philosophy and Humanities Udmurt State University

Universitetskaya st., 1/6, Izhevsk, Russia, 426034

E-mail: repnikov@udm.ru 